\title{
Minimum Data Set for EMS Report Form: Historical Development and Future Implications
}

\author{
Jerris R. Hedges, MD, MS, FACEP, ${ }^{\dagger}$ Steven M. Joyce, MD, FACEP ${ }^{\dagger \dagger}$
}

\begin{abstract}
Report forms are used by Emergency Medical Services (EMS) systems for documentation of services provided and for self-analysis of EMS functions. Although the EMS Systems Act of 1973 originally intended for the development and implementation of a uniform EMS report form, items recorded on EMS forms vary throughout the United States. We review the governmental sponsored development of a recommended minimum data set (MDS) for EMS forms performed in 1974, and discuss areas of needed investigation regarding data set development and usage. The concepts used to develop the recommended MDS provide a useful resource for review of the purpose and content of one's own EMS report form. However, future data set development and applications should use outcome measure guided data set selection, on-line validation of data item accuracy and recordability, psychometric analysis of the process of form completion, and incorporation of new data entry and storage technology.
\end{abstract}

\section{Introduction}

The Emergency Medical Services (EMS) system report form is part of the patient's legal medical record and should identify the patient and note his or her condition and treatment. The EMS report form also is a productive means of assessing the performance of prehospital care systems. Standardization of information collected on EMS report forms has been suggested to facilitate comparison of EMS functions between different geographic areas and national entities.

In the United States, 29 states have uniform EMS data report forms. ${ }^{1}$ However, many states have left the choice of the EMS report form to each local prehospital care system. To provide reference information which can be used by EMS systems for modification and adaptation of their current report form, we describe the historical development of a governmental sponsored recommended minimum data set (MDS). We also address areas of investigative need for future data set development.

\section{Development of the Original MDS}

A "minimum data set (MDS) for EMS patient record keeping" was recommended by Macro Systems, Inc. ${ }^{2}$ as a guide for developing EMS systems funded by the Health Services Administration (HSA) in compliance with the enactment of the

\footnotetext{
$\dagger$ Division of Emergency Medicine, Oregon Health Sciences University

$+\dagger$ Section of Emergency Medicine, University of Utah

Address Correspondence to: Jerris R. Hedges, MD, Division of Emergency Medicine Oregon Health Sciences University, 3181 S.W. Sam Jackson Park Road, Portland, OR 97201, USA
} 


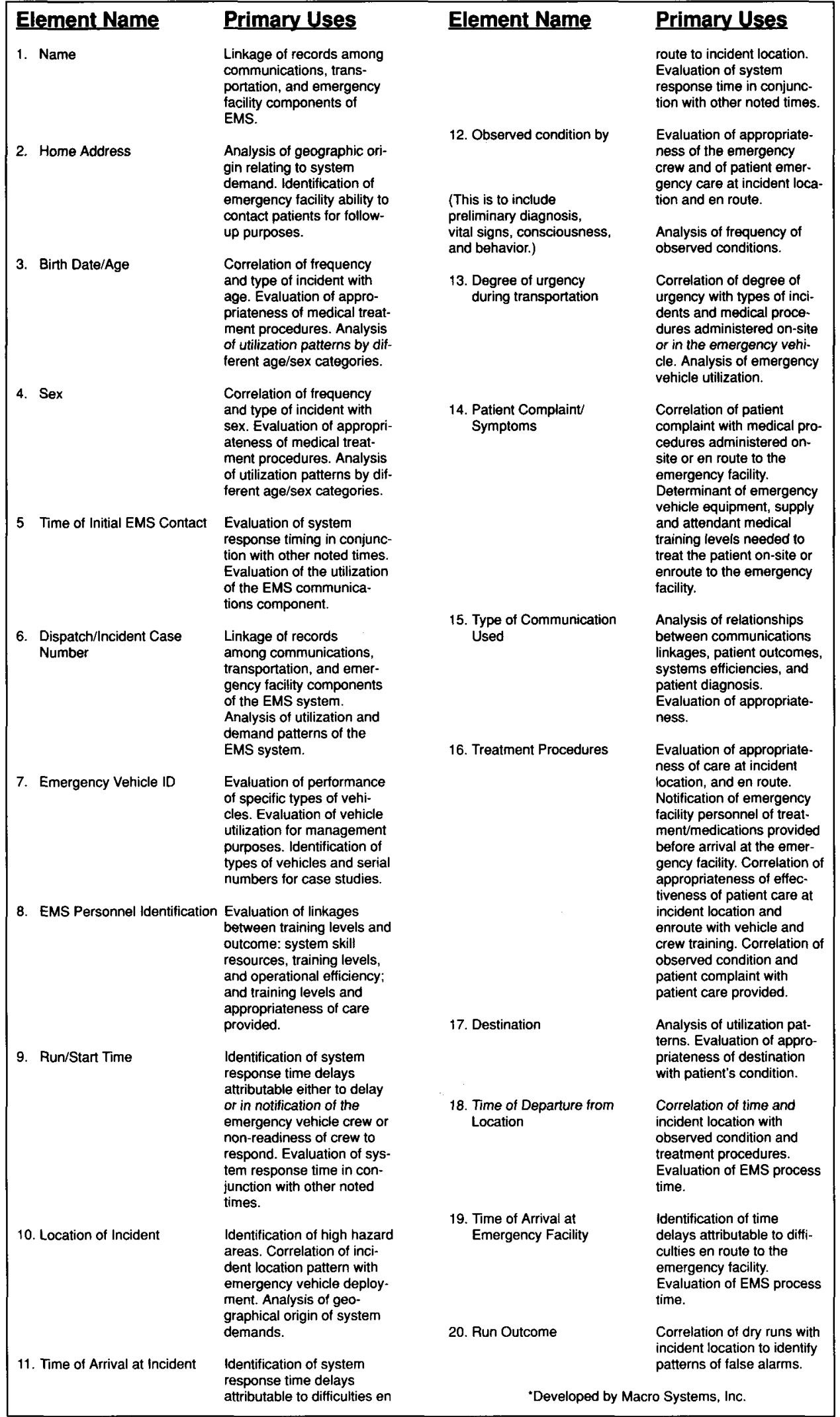

Table 1 - Minimum EMS Data Set ${ }^{*}$

Prehospital and Disaster Medicine $\bullet 1990$ Hedges, Joyce


EMS Systems Act of $1973 .{ }^{3}$ Under Section 1206 (b) (4) (C) (xi) of the law, the sponsored EMS systems were to "provide for a standardized patient record keeping system meeting appropriate standards established by the Secretary, which records shall cover the treatment of the patient from initial entry into the system through his discharge from it, and shall be consistent with ensuing patient records used in follow-up care and rehabilitation of the patient."

Although a uniform data set was deemed necessary by Congress, the actual implementation of this data set has not evolved as suggested by law. Macro Systems, Inc., through their discussions with the HSA, concluded that imposition of an absolute uniform record keeping form or procedure upon evolving or established EMS systems was both unfeasible and unnecessary to accomplish the intent of the EMS Systems Act. This conclusion was based upon three assumptions: 1) Each EMS system was heterogenous and in all likelihood, the composite organizations already had developed and were satisfied with their own forms and data collection procedures. Furthermore, most of the forms in use were likely to contain the items that could form the basis of a uniform record keeping system; 2) The HSA and EMS grantees had limited authority to impose new or uniform record keeping upon the constituent entities. Tying the use of a standard form to financial assistance possibly would have discouraged participation with the EMS Act; and 3) The EMS system grantees were heterogenous and no uniform record keeping approach would be likely to serve all the needs of each EMS system because of variations in system structure, operations, and objectives. Therefore, the HSA decided to develop a minimum set of data items that were likely to be included in existing report forms or would represent only a minor inconvenience when upgrad- ing existing EMS system forms to include such items.

Due to a severe time constraint, the contracting agency used five steps to develop the MDS. First, the goals, objectives, and essential structure of EMS systems were examined. Because the overall goal of an EMS system is "to reduce avoidable death or disability from accidents and sudden illnesses through the rapid provision of competent EMS when needed," each EMS system had to address four main objectives to meet this goal: "( 1 ) deployment of resources in a manner most likely to assure prompt access to EMS when needed by all individuals within the system service area; (2) efficient utilization of these EMS resources as they are deployed; (3) assurance that the service provided to individuals who enter the EMS system, particularly services in the direct patient care area, are appropriate to the medical conditions of those individuals in that they are consistent with professionally accepted standards of care; and (4) containment of EMS system costs."

The EMS data form was expected to support the management and subsequent evaluation of the EMS system in each of the above areas. In pursuit of these objectives, each EMS system must coordinate direct patient service (EMS communications, rescue and ambulance services, emergency departments or other fixed facilities) and support functions (system financing, training of EMS personnel, and public education). Because patient record keeping systems interface only with the direct patient service functions, only the first three components of the EMS system were considered in the development of the MDS.

Second, the agency reviewed the overall functions of the EMS system from patient access and system activation to patient care in an emergency facility. They reasoned that administrators would wish to know: "(1) who was using the system and for what pur- 
poses; (2) how the communications and rescue/ambulance service components responded to requests for assistance; (3) what conditions were encountered by a rescue/ambulance crew and how the crew responded to those conditions; (4) what conditions were observed by emergency department personnel, and what services were rendered in response to those conditions; and (5) how the patient left the EMS system."

Third, the agency evaluated sixty existing medical forms. Because of limited time availability, there was no random sampling and only forms that were immediately available to the agency were reviewed. The majority of these forms did not address the prehospital phase of EMS care. In fact, only fifteen of the sixty forms analyzed were related to prehospital care. A tabulation was made to determine how many times in each of the sixty forms various data items were included and expressed in a particular terminology. Several hundred discrete data elements were noted on the sixty forms but no single data element appeared on all sixty. The agency noted that the most common element was patient name, but several forms omitted even this basic element.

The agency developed a preliminary list of data elements for the MDS. A data element was considered important if it met all of the following criteria: "(1) it had significant value for planning, controlling, or evaluating an EMS system; (2) it already was collected by a high percentage of existing EMS recordkeeping systems, or it could be collected readily without imposing an excessive burden on EMS operational or clerical personnel; and (3) it was capable of being expressed in objective terms." On the other hand, a candidate data element was rejected if it met either of the following criteria: "(1) it was highly dependent on subjective judgment; or (2) it could not be expressed either as (a) a numeric value, or range of numeric values, (b) an item from a set of discrete items; (c) the presence or absence of a specific condition or activity; or (d) a universally understood identifying label for a person, place, or physical resource."

In order to achieve the objectives noted, the project team then developed a list of measures that should be available for managing and evaluating EMS performance. "For each such measure, the project team identified data elements which would be needed to construct the measure and also would meet the criteria described." Initially, the project team concluded that 23 data elements would satisfy the most important requirements of EMS system management and evaluation, of which 14 would be collected normally by the communications and transportation components of the system and nine would be collected normally in the emergency department. Another 14 data elements were identified as highly desirable but not essential, of which eight were related to communications and transportation and six to emergency department function.

Fourth, the tentative EMS-MDS was critiqued during four site visits and a seminar. Input was obtained from the University Association for Emergency Medicine (now the Society for Academic Emergency Medicine) and the American College of Emergency Physicians.

Fifth, the tentative MDS was modified and refined and a draft EMS record keeping system handbook was prepared. At the time, there were 17 data elements relating to transportation and communication. Subsequent analysis and input led to the addition of three more items. The full MDS list is in Table 1. These items never were field tested formally. However, it is likely that EMS systems that were aware of the development of the MDS incorporated these items into their EMS forms. 


\section{Discussion}

The EMS report form has many applications. The form does more than identify the patient and document the treatment used. The form provides the mechanism for analyzing EMS system performance. Supervising physicians and EMS administrators from different systems will have different concerns and perspectives. Hence, different data items for the different data forms will be needed to address various performance issues. Nonetheless, comparison of systems requires some uniformity in data item collection and definition.

Although comprehensive EMS data sets have been developed which include many report form items and address a multitude of EMS system needs, ${ }^{4,5}$ the basic process of outcome guided item selection remains relevant today. The limited on-line investigation of the data sets or specific items currently in use remains a concern. Scholarly examination of the application of data items and other aspects of data collection presents a fertile area for EMS research.

Areas needing investigation include the accuracy of data recording and frequency of data item use. For example, how accurately are data items recorded that have been recently introduced, such as trauma scores or other physiologic indices? Do some data items appear on the report forms of many systems, but seldom are used? What is the inter-observer variability for each of these factors?

Similarly, we need to review how data items correlate with the outcomes we are seeking to modify. For example, do scene times affect outcome? Such a process requires that we carefully define the outcome that we wish to correlate with our data items. Do we wish to see happier patients, patients with better physiologic indices upon hospital arrival, more surviving patients, shorter hospital stays, or more patients released home from the emergency department as a result of aggressive prehospital care? Clear patient outcome measures are needed for monitoring care and establishing correlations with report form data items.

Some data set items may serve as a barometer of prehospital care in the community. For example, an increase in the number of cardiac arrest patients with asystole (or very fine ventricular fibrillation) may suggest that the system response times have slowed. This concern can be addressed by examining response times for basic and advanced life support teams. Hence, the interrelationship of data items is an important area in need of further investigation.

The process of data collection as affected by patient care demands, time availability, and report form factors (e.g., number of items and form layout), should be evaluated from a user perspective. Study of the psychometrics of report form completion is needed. The role of new report form technology requires investigation as well. Do optical scan forms improve the quality or quantity of data obtained? How might records be entered directly into computers and how will data collection, transferral, analysis, and confidentiality be affected by direct computer use?

\section{Conclusions}

As financial issues increase in importance and emergency medical services (EMS) systems are required to provide better documentation of the services provided and their efficacy in providing care, the EMS report form will be expected to provide these data. Current data items and handwritten multicopy report forms should not be considered sufficient. Emergency medical services administrators, supervising physicians, and care providers need systematically to review the use of their current EMS report form and technique of data collection and storage. While the process outlined in this paper records a bench mark approach 
to data set development, future efforts will require a combination of consensus development, outcome measure guided data item selection, on-line validation of data item accuracy and recordability, psychometric analysis of the process of form completion, and incorporation of new technology.

\section{References}

1. Eleventh Annual EMS State and Province Survey: Emergency Medical Services 1987; 16:203-241.

2. Steele R: Development of a minimum data set for emergency medical services patient record keeping. July 1974; National Technical Information Service, PB243822.

3. The 93rd U.S. Congress, First Session: Emergency Medical Services System Act of 1973. November 16, 1973. Public Law 93154, 87 STAT. 594.

4. Joyce SM, Criss E: Guidelines for development of EMS reporting forms: A nationwide survey. Ann Emerg Med 1987;16:508 (Abstract).

5. Joyce SM, Witzke D, Brown D, et al: Development of an optically-scanned EMS reporting form and database for statewide use. Ann Emerg Med 1987;16:508 (Abstract). 


\section{National Association of EMS Physicians}

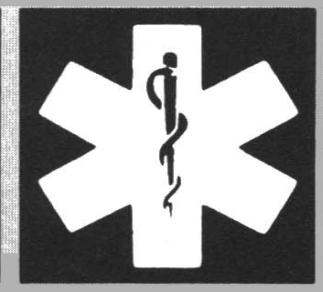

\section{QUALITY ASSURANCE PROGRAM}

This two-day meeting will address multiple aspects of quality assurance through didactic lectures as well as comprehensive workshops dealing with specific areas of prehospital care in a variety of systems.

\section{PRELIMINARY PROGRAM}

- Defining Quality Assurance

- Administrative Support: Who Pays For Quality Assurance?

- Defining the Scope of Quality Assurance

- The Medical Director's Role

- How Different Systems 'Do It'

- Hospital's Perception vs EMS System's Perception of Quality Assurance

- Closing The Loop: The 4 Classical Ways of Dealing with Quality Assurance

- Development \& Setting Standards for Quality Assurance

- Evaluating Care: How Does Research Affect Quality Assurance?

- Quality Assurance Affecting Systems: ASL/BLS/URBAN/Non-Urban

- Comprehensive Workshops Catering To Specific Needs

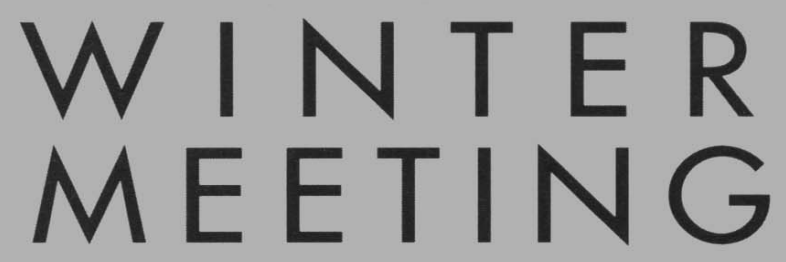

\section{ON QUALTY ASSURANCE}

JANUARY 18-19, 1991

Sheraton-Sand Key Resort

CLEAR WATER BEACH，FLORIDA

A useful meeting for all EMS System

Personnel: Inviting

Administrators

Managers

Medical Directors

Supervisors

Paramedics

EMTs, Nurses

and all members of the

Prehospital Care Community

\section{RASERVE YOUR SPACE FOR C.A. IN THE SUNI}

Complete the following reservation card and mail to: Kathleen Stage, National Coordinator NAEMSP 230 McKee Place, Suite 500 Pittsburgh, PA 15213

Name

Organization Address

City / State / Zip

Call (800) 228-3677 or (412) 578-3222 


\section{Subscription and Business Information for the Readers of \\ Prehospital and Disaster Medicine}

\section{SUBSCRIPTION PRICES}

$\begin{array}{ll}\text { One-year } & \text { Two-year } \\ \text { (4 issues) } & \text { (8 issues) }\end{array}$

Institutional $\ldots \ldots \ldots \ldots \ldots \ldots \ldots \ldots 78 \ldots \ldots \ldots 148$

Individual $\ldots \ldots \ldots \ldots \ldots \ldots \ldots \ldots \ldots 8$

Resident/In Training . . . . . . . . .\$35 . . . . . \$ 65

EMT/Paramedic/Nurse . . . . . \$35 ... . .\$65

Note: "Institutional Subscribers" are defined as multiple reader subscribers and include public and private libraries, schools, hospitals and clinics; city, county, state, provincial and national government bureaus and departments; and all commercial and private institutions and organizations.

Individual subscriptions and all student-rate subscriptions must be in the name of, billed to, and paid by individuals. All studentrate requests must indicate training status and name of institution.

Send U.S. subscription orders to: Jems Publishing Company, PDM, P.O. Box 1026, Solana Beach, CA 92075; 619/481-1128; FAX: 619/481-2711.

\section{INTERNATIONAL SUBSCRIPTIONS}

International subscription orders should be directed to: Jems Publishing Company, P.O. Box 1026, Solana Beach, CA 92075; telephone: 619/481-1128; FAX: 619/481-2711. Canadian subscribers add $\$ 10$ per year for postage and handling. Please include payment in U.S. funds. All other international subscribers add $\$ 20$ per year.

\section{GHANGE OF ADDRESS \& MISSING ISSUES}

Please let your subscription representative know as soon as possible when you plan to move. We need four to six weeks advance notice for uninterrupted service. Send us your 1) current mailing label (with old address), 2) your new address and 3) effective date of change. If you did not receive an issue, let us know within three months of cover date.

If you have other questions about your subscription, please address them to: Customer Service, Jems Publishing Company, P.O. Box 1026, Solana Beach, CA 92075.

\section{EDITORIAL INFORMATION}

Please address all manuscript and editorial inquiries and comments to: Marvin L. Birnbaum, Editor, Prehospital and Disaster Medicine, 1552 University Ave., Rm. 434, Madison, WI 53705; 608/263-2069 or 608/263-7094; FAX: 608/263-2069.

\section{ASSOCIATION CONTACTS}

National Association of Emergency Medical Services Physicians, Executive and National Resource Center, 230 McKee Place, Suite 500, Pittsburgh, PA 15213; 1-800/228-3677.

World Association for Emergency and Disaster Medicine, Dr. Peter J.F. Baskett, President, Dept. of Anaesthesia, Frenchay Hospital, Bristol BS 16 1LE, United Kingdom.

Acute Care Foundation, P.O. Box 90193, Lakeland, FL, 338040193; 813/539-7352.

National Association of State EMS Directors, Council of State Governments, P.O. Box 11910, Lexington, KY 40578-1910; 606/252-2291.

\section{JEMS - Your Monthly Guide to EMS}

$J E M S$ was created ten years ago with one goal in mind: to provide the top men and women of EMS with a monthly journal that would serve them as well as they serve their patients. Publisher Jim Page has been involved in EMS for over 30 years as a rescuer, administrator, attorney, lecturer and writer. He designed a journal that would feature lively writing and graphics to match the dynamic growth of the EMS industry.

\section{You'll find in JEMS:}

- Monthly case studies of actual prehospital calls for CEU credit for EMTs and paramedics.

- "Tricks of the Trade" to enhance your patient care skills.

- Up-to-date news on the people and events that affect your job.

- A yearly salary of all EMS personnel-how does your department compare?
- Comprehensive information resources on all aspects of EMS

- Annual buyer's guide with the most complete and accurate listing of products, services, manufacturers and distributors.

- Essays and opinion on the issues you face everyday on the street, in the classroom and in your organization.
Photographs and artwork that explain and entertain.

- Interpretive reports on the current research.

- Regular columns on pediatric care, EKG interpretation, clinical questions and answers, new books and new products.

- Regular columns on quality assurance, instructor training, the public/private interface and legal issues.

To subscribe, please fill out the attached card.

If missing, please send a check for $\$ 19.97$ for a year's subscription (12 issues) to:

JEMS, P.O. Box 1026, Solana Beach, CA 92075 
